\title{
ASSINATURA DIGITAL: SEGURANÇA E PROVA NAS CONTRATAÇŌES ELETRÔNICAS
}

\author{
DIGITAL SIGNATURE: SECURITY AND EVIDENCE IN THE \\ ELECTRONICS CONTRACTS
}

Vinicius Roberto Prioli de Souza ${ }^{1}$

\section{Sumário}

1. Aspectos gerais do documento eletrônico. 2. Assinatura digital e a validade dos documentos eletrônicos. 3. A necessidade da assinatura digital e a utilização do documento eletrônico como meio de prova. 4. A infraestrutura de chaves públicas no sile os efeitos jurídicos da assinatura digital. 5. Consideraçōes finais. Referências.

\section{Summary}

1. General aspects of electronic document. 2. Digital signature and electronic documents validity. 3.The necessity of digital signature and the use of electronic document as evidence. 4. Public keys' infrastructure in Brazil and the legal effects of digital signature. 5. Final remarks. References.

\section{Resumo}

Neste trabalho analisa-se a assinatura digital como forma de proporcionar segurança e meio de prova nas relações contratuais celebradas por intermédio da internet. O objetivo principal desse tipo de assinatura é conferir autenticidade ao documento criado em ambiente virtual, indicando como e quando determinado documento foi gerado na internet e quem é o responsável, tornando esse ato válido e eficaz para fins jurídicos. A presente pesquisa utilizou uma metodologia dedutiva, por meio de uma abordagem interdisciplinar. Como procedimento, adotou-se, a forma documental indireta com pesquisa documental e bibliográfica do tema. Este estudo transmite uma visão geral da funcionalidade, utilidade e viabilidade dos meios de segurança existentes para a realização de contratos em ambiente virtual. Conclui-se que a assinatura digital, digitalmente certificada, é um elemento primordial para validar o contrato eletrônico.

Palavras-chave: Contratos eletrônicos. Certificação digital. Assinatura digital.

1 Professor na Faculdade de Direito de Itu-FADITU. Advogado. Mestre em Direito pela Universidade Metodista de Piracicaba-SP - UNIMEP. 


\begin{abstract}
This study examines the digital signature as a way to provide security and evidence in contractual relations concluded through the Internet. The main purpose of this type of signature is to provide authenticity to the document created in virtual environment showing who, how and when the document was created, making this act valid and effective for legal purposes. This research used a deductive methodology, through an interdisciplinary approach. We used documentary research and literature of the subject as indirect procedure. This paper is an overview of the functionality, utility and feasibility of security means in making contracts in virtual environment. Thus, it was possible to conclude that the digital signature, digitally certified, concerns a key component to make the contract valid.

Key-words: Electronic contract. Digital certification. Digital signature.
\end{abstract}

\title{
1 Aspectos gerais do documento eletrônico
}

No que diz respeito aos contratos firmados por meio da internet, é inquestionável a discussão quanto à sua segurança. Essa questão preocupa todos aqueles que utilizam essa rede para contratar, tais como os consumidores de bens. Tal discussão norteia-se no que tange à validade, autenticidade, confiabilidade e integridade dos documentos eletrônicos, pois, se os indivíduos já são cautelosos ao ler, elaborar ou assinar um documento no mundo real, que dirá no meio virtual.

Por documento, segundo José Frederico Marques, entende-se "a prova histórica real, visto que representa fatos e acontecimentos pretéritos em um objeto físico, servindo assim de instrumento de convicção" ${ }^{2}$.

Já para Moacyr Amaral Santos, documento é "a coisa representativa de um fato e destinada a fixá-lo de modo permanente e idôneo, reproduzindo-o em juízo"3.

Diante do exposto, é possível apreender que, ao longo dos tempos, os doutrinadores têm reconhecido o documento como uma forma de prova concreta, material ou, ainda, sob outro prisma, pode-se entender o documento como algo palpável, capaz de representar um fato acontecido; trata-se de um meio de representação do fato que se quer provar, ou seja, uma representação fática do acontecimento, servindo, assim, de prova para comprovar a existência ou ocorrência desse fato.

Se for tomado por base que o documento é uma coisa representativa de um fato, como ensina Moacyr Amaral Santos, não se pode dizer, em momento algum, que o documento eletrônico é, de fato, um documento, visto que ele não

2 MARQUES, A. T. G. L. A prova documental na internet. Curitiba: Juruá, 2007, p.122.

3 Idem, p.122. 
é uma coisa e, portanto, não poderá ser representativo de um fato. Não é possível pensar na noção de documento apenas como uma coisa tangível, pois, assim, não se conseguirá definir o documento eletrônico, posto que este seja intocável, impalpável e etéreó ${ }^{4}$.

Uma conceituação consideravelmente coerente a respeito do documento eletrônico é fornecida por Aldemario Araújo Castro. Para o autor, ele é

[...] a representação de um fato concretizada por meio de um computador e armazenado em formato específico (organização singular de bits e bytes), capaz de ser traduzido ou apreendido pelos sentidos mediante o emprego de programa (software) apropriado 5 .

Outras definições foram dadas ao referido documento. Fabiele Behrens, por exemplo, afirma que:

O documento eletrônico, também denominado de documento digital ou informático, é produzido por meio da utilização de computador. Ou seja, é a formação de um documento com o uso de uma nova tecnologia. Este documento, ainda, pode ser considerado como aquele que se encontra inserido e gravado em formato digital, ao alcance dos envolvidos, apenas, com a utilização do computador e de um programa adequado, em especial com a utilização da assinatura digital conferindo segurança e confiança aos dados armazenados ${ }^{6}$.

Dessa forma, a lógica leva a compreender que, assegurando a certeza, a segurança, a impossibilidade de alteração do documento e a possibilidade de determinação dos sujeitos, pode-se definir o documento eletrônico como uma espécie de representação da realidade, sob a aparência gráfica, sonora, impressa ou qualquer outra forma ${ }^{7}$.

Ressalte-se, também, que o documento eletrônico registra o fato ocorrido, representando a vontade de seu autor, requisito que basta para que ele se encaixe na definição de documento, o qual, formado por uma sequência de bits, poderá ser traduzido por um software, dando conhecimento à verdadeira vontade do autor que o formulou ${ }^{8}$.

4 BRASIL, A. B. Assinatura digital. Jus Navigandi. ano. 4. n. 40. Teresina, mar. 2000. Disponível em: <http://jus2.uol.com.br/doutrina/texto.asp?id=1782>. Acesso em: 13 set. 2007.

5 CASTRO, A. A. O documento eletrônico e a assinatura digital. Disponível em: <http://jus2.uol.com. br/doutrina/texto.asp?id=2632\&p=2>. Acesso em: 13 set. 2007.

6 BEHRENS, F. Assinatura eletrônica \& negócios jurídicos. Curitiba: Juruá, 2007, p.65.

7 Ibidem., p. 66.

8 BRASIL, A. B. op. cit., mar. 2000. 
A relação existente entre o comércio eletrônico e a geração dos documentos eletrônicos é estreita; logo, quanto maior se tornar o comércio no meio virtual, mais ampla será a necessidade de documentos eletrônicos que comprovem a validade e a existência dos negócios jurídicos realizados em tal meio?.

Não é demais lembrar que o desenvolvimento da tecnologia da informação e dos meios de comunicação, a fim de aprimorar-se o comércio eletrônico, seria desnecessário se não houvesse proteção alguma ao objeto das relações decorrentes desses avanços, tais como os contratos e os documentos eletrônicos.

Um posicionamento mais crítico levaria à ideia de que as normas contemporâneas deverão ser reavaliadas, já que essa nova forma de contratar baseia-se na troca de documentos eletrônicos, e não somente no valor jurídico conferido ao documento em suporte físico, palpável, impresso em um papel. Em outras palavras, e seguindo a linha crítica de Gustavo Testa Corrêa, "os documentos eletrônicos deverão ter a mesma validade de um documento em papel, original e assinado ${ }^{10}$.

\section{Assinatura digital e a validade dos documentos eletrônicos}

Para empreender uma análise quanto à existência e validade dos documentos eletrônicos, seja pela legislação aplicável ao documento, seja pelas consideraçôes sobre sua materialidade, deve-se, antes de tal procedimento, conhecer duas correntes de pensamentos. A primeira corrente sustenta a impossibilidade jurídica dos documentos eletrônicos, enquanto a segunda aceita a existência e a validade deles. Esse último pensamento divide-se em duas vertentes: a primeira aceita o documento eletrônico como realidade jurídica válida por si só, enquanto a segunda admite a existência e validade dos documentos eletrônicos, desde que atendam certos requisitos, em decorrência de sua volatilidade e falta do traço personalíssimo de seu autor ${ }^{11}$.

Afastando os critérios de interpretação literal do documento, a qual restringe sua definição, pode-se tranquilamente entender que a existência dos documentos eletrônicos em si não poderá ser recusada, de acordo com o constante nos artigos 368, 369, 371, 374, 376, 386, entre outros, do Código de Processo Civil (CPC). Deve-se utilizar um raciocínio hermenêutico e sistemático a fim de interpretar de forma correta a definição de documento eletrônico; afinal, se a aceitação de um contrato verbal é inquestionável, o mesmo ocorre na forma eletrônica ${ }^{12}$.

9 CORRÊA, G. T. Aspectos jurídicos da internet. São Paulo: Saraiva, 2000, p. 41.

10 Ibidem., p. 41.

11 CASTRO, A. A. op. cit.

12 Ibidem. 
Não exige um exercício reflexivo muito árduo compreender que a assinatura é um dos requisitos que comprovam a autenticidade e integridade de um documento elaborado no mundo real; do mesmo modo ocorre no mundo virtual, pois, segundo Angela Bittencourt Brasil, "a assinatura tal qual hoje se reconhece pode ser conceituada como sendo o ato físico por meio do qual alguém coloca em um suporte físico a sua marca ou sinal, sendo personalíssima"13.

Contudo, assim como a assinatura pode ser fraudada no mundo real, ela também pode sofrer tal ilícito no mundo virtual. No mundo real, as assinaturas são falsificadas e os documentos são forjados; no espaço virtual isso também ocorre. A assinatura digital equivale à assinatura manuscrita, tendo em vista que o objetivo de ambas é comprovar a autenticidade e integridade de determinado documento, tornando-o válido.

Qualquer agente social possui plena capacidade de entender que a assinatura digital tem diferenciações em comparação à assinatura manuscrita, pois ela não corresponde a esta como se verifica comumente. Insta informar que, em sentido amplo, ela constitui um sinal passível de ser usado com exclusividade e ligado a um documento com o objetivo de comprovar sua autoria de forma inequívoca, revelando a identidade da pessoa e manifestando a sua vontade, no sentido de manifestar concordância com o conteúdo de tal documento ${ }^{14}$.

Pela assinatura manuscrita, identifica-se um determinado sujeito como se esse registro fosse sua marca (na verdade é); já a assinatura eletrônica deve ligar um determinado indivíduo a um documento e, ainda, garantir a autenticidade e integridade do conteúdo deste.

Estudiosos do assunto, como João Agnaldo Donizeti Gandini, Diana Paola da Silva Salomão e Cristiane Jacob contribuem qualitativamente com a presente pesquisa quando explicam que:

A verificação da integridade de um documento diz respeito à avaliação que se faz sobre ter sido ele modificado ou não, em alguma ocasião após sua concepção. Quando nos referimos aos documentos fixados em um suporte físico, a investigação poderá ser feita mediante exame do próprio continente em que se encontra afixado. Desta forma, constataremos se há ou não alteração. No caso dos documentos digitais esta verificação é determinada pela assinatura digita ${ }^{15}$.

Em outras palavras, por possuir essa obrigação, a assinatura eletrônica utiliza elementos do texto junto com elementos da identidade do autor, unindo-os

13 BRASIL, A. B. op. cit., mar. 2000.

14 BOIAGO JÚNIOR, J.W. Contratação eletrônica: aspectos jurídicos. Curitiba: Juruá, 2005, p.74.

15 GANDINI, J. A. D.; SALOMÃO, D. P. S.; JACOB, C. A Segurança dos documentos digitais. Disponível em: <http://jus2.uol.com.br>. Acesso em: 19 ago. 2005. 
numa espécie de fórmula matemática que garantirá sua autoria e autenticidade. Isso leva a compreender que a assinatura digital deve, obrigatoriamente, possuir uma variação, que inclui dados do documento na qual é inserida, enquanto nossa assinatura manuscrita, ao contrário, deve ser sempre igual, a fim de gerar a mesma presunção.

Os autores recém-citados dão outra parcela de contribuição, ao constatarem que:

Sendo o suporte do documento o papel, fica fácil apurar qual sua idade, com a utilização das técnicas apropriadas, pois até mesmo a forma de impressão e tipo de tinta serão importantes para determinarmos a origem e a data de sua produção, pois nos informarão se são condizentes com a tecnologia disponível na época de sua feitura. Igualmente, pode-se detectar a data da feitura de um documento digital por meio da assinatura digital ${ }^{16}$.

O conjunto de ideias levado a efeito até o momento nesta seção propicia o entendimento de que a assinatura manuscrita será sempre a mesma; já a digital será sempre diferente, posto que haverá uma assinatura digital para cada documento assinado eletronicamente. Sob tal ótica, uma vez que o documento eletrônico se encontre assinado digitalmente por seu autor, ele possuirá validade jurídica, já que a assinatura digital confere existência e validade a esse tipo de documento.

Para finalizar o assunto e ilustrar com um exemplo significativo, urge expor que em países mais avançados em relação à validade da assinatura digital, por exemplo, os Estados Unidos da América, existem leis que conferem validade à assinatura digital, equiparando-a com a assinatura em documentos físicos. Em 10 de janeiro de 2000, entrou em vigor nesse país a lei para a uniformização das transações eletrônicas - Uniform Electronic Transactions Act (Ato Uniforme de Transações Eletrônicas) -, atribuindo à assinatura digital os mesmos efeitos legais da assinatura manuscrita, desprendendo-se, assim, da exigibilidade da assinatura manuscrita nos tradicionais documentos em pape ${ }^{17}$.

\section{A necessidade da assinatura digital e a utilização do documento eletrônico como meio de prova}

Esta pesquisa pode até parecer redundante em algumas situações, mas é proposital o fato de algumas informaçóes importantes serem repetidas mais de uma vez, até mesmo o fato de que a assinatura digital visa garantir a autenticidade

16 BOIAGO JÚNIOR, J. W. Contratação eletrônica: aspectos jurídicos. Curitiba: Juruá, 2005.

17 CORRÊA, G. T. op. cit., p. 42. 
e a integridade ao conteúdo do documento eletrônico após sua "assinatura" pelo autor. Significa maior segurança e validade aos negócios eletrônicos e às transações realizadas pela Internet, pois se trata de uma identificação segura para os que realizam negócios utilizando-se do meio virtual. Cabe ressaltar que esse tipo de assinatura sempre foi objeto de desejo de ambas as partes envolvidas nos negócios on-line, empresários ou consumidores.

No que tange à celebração de contratos eletrônicos, a insegurança consiste principalmente em ainda não haver normas específicas aplicáveis a essa nova forma contratual, bem como a dificuldade para a identificação das partes contratantes. No entanto, essa realidade está gradativamente alterando-se.

Com a utilização da assinatura digital, os documentos eletrônicos passam a ter existência e validade no mundo jurídico, podendo constituir meios de prova da existência de certos negócios jurídicos que neles estão contidos; constituem uma forma de o autor manifestar sua vontade nos contratos eletrônicos, levandose em conta a certeza, a segurança e a confiança neles existentes, em decorrência da assinatura digita ${ }^{18}$.

Dinemar Zoccoli ${ }^{19}$, no artigo "Autenticidade e integridade dos documentos eletrônicos: a firma eletrônica”, explica que existem diversas formas de se assinar um documento eletrônico, bem como métodos mais simples para promover tal assinatura, tal como a inserção da imagem de uma assinatura manuscrita transpassada para a forma digital num documento feito com tratamento de texto. Há também métodos mais complexos e avançados, como as assinaturas digitais desenvolvidas a partir da criptografia assimétrica, as quais possibilitam aos usuários, que venham a receber os documentos eletronicamente, verificar sua origem, autenticidade, integridade e validade e conferir se todos os dados estão completos e inalterados. As assinaturas digitais conferem tanto a autenticidade da fonte dos dados enviados eletronicamente como a integridade destes.

Mônica Viloria Méndez, ao tratar da liberdade probatória como garantia constitucional da defesa, explica que:

Esta liberdad de medios probatorios, expresión de la garantía constitucional de la defensa, permite a las partes acreditar sus afirmaciones utilizando cualquer medio probatorio idóneo enumerado o no en la ley. De modo que la inercia del legislador respecto del caráter de medio de prueba de los documentos y registros electrónicos, se ve subsanada por la posibilidad de las partes de utilizar estos nuevos documentos para acreditar sus afirmaciones. En todo caso, la parte promovente del documento

18 BEHRENS, F., op. cit., p.63.

19 ZOCCOLI, D. Autenticidade e integridade dos documentos eletrônicos: a firma eletrônica. In: ROVER, A.J. (Org.). Direito, sociedade e informática. Florianópolis: Fundação Boiteux, 2000. p.180. 
electrónico deberá demostrar la conductibilidad del medio, esto es, su capacidad de conducir el hecho afirmado al expediente.

De modo pues que, gracias al principio de la libertad de medios, la demonstración de un contrato o de un evento con trascendencia juridica en internet, podria ser alcanzado através de un cúmulo de pruebas mencionadas en las leyes existentes o $\mathrm{no}^{20}$.

Segundo essa explicação, parece ficar claro quanto à plausibilidade da validade e eficácia jurídica dos documentos eletrônicos, pois se trata de uma nova realidade jurídica, ocorrida em função dos avanços tecnológicos existentes nas formas de contratação. $\mathrm{O}$ ordenamento jurídico pátrio possui normas elásticas quanto à aceitação dos meios de prova, possibilitando atribuir validade e eficácia jurídica probatória ao documento eletrônico por intermédio da interpretação de alguns dispositivos legais ${ }^{21}$.

Por fim, resta cientificar o leitor de que os documentos eletrônicos são meios de prova idôneos, não infringindo normas de direito material, pois se mostram capazes de possibilitar o convencimento e, também, apresentam-se como um meio de prova legítimo, legal e moralmente aceitos ${ }^{22}$.

\section{A infraestrutura de chaves públicas no Brasil e os efeitos jurídi- cos da assinatura digital}

Como já exposto anteriormente, sabe-se que é por meio da criptografia assimétrica que a assinatura digital é desenvolvida, e o Brasil não ficou alheio a esse desenvolvimento, tampouco ignorou os avanços legislativos internacionais acerca do assunto.

Como exemplo do posicionamento brasileiro diante do problema, foi criada, em junho de 2001, a Infraestrutura de Chaves Públicas Brasileira (ICPBrasil), por intermédio da Medida Provisória (MP) no 2.200, originada do Decreto $\mathrm{n}^{\mathrm{o}} 3.587$, de 5 de setembro de 2000, o qual, por sua vez, instituiu a Infraestrutura de Chaves Públicas do Poder Executivo Federal, chamada de ICP-Gov. Tal decreto previa a utilização da criptografia assimétrica nas transações eletrônicas seguras e a troca de informaçóes sensíveis e classificadas, cuja finalidade era iniciar o processo de substituição dos documentos físicos que tramitavam entre os órgãos do governo pelos meios eletrônicos, agilizando, assim, a transmissão dos expedientes ${ }^{23}$.

20 MÉNDEZ, M. V. Las Pruebas en el Comercio Electrónico. Revista de Derecho Informático. Disponível em: <http://www.alfa-redi.org>. Acesso em: 26 set. 2007.

21 MARQUES, A. T. G. L. op. cit., p.144-145.

22 Ibidem, p.148-149.

23 MENKE, F. Assinatura eletrônica: aspectos jurídicos no direito brasileiro. São Paulo: Revista dos Tribunais, 2005, p. 97-98. 
As determinações constantes no citado decreto serviram como alicerce para a instituição da MP no 2.200, editada em 28 de junho de 2001. A principal diferença existente entre tais normativas diz respeito à sua incidência. $\mathrm{O}$ decreto possuía incidência exclusiva no âmbito da Administração Pública Federal; logo, mesmo que as autoridades certificadoras partissem de iniciativas privadas, os destinatários dos serviços de certificação digital deveriam fazer parte da esfera da administração citada.

Fator importante a ser considerado é que, com a criação da ICP-Brasil, deixou-se de atender com exclusividade a Administração Pública Federal, ampliando essa função a qualquer usuário que tivesse o desejo de adquirir um certificado digita ${ }^{24}$.

No que se refere à $\mathrm{MP} \mathrm{n}^{\circ} 2.200$, há que se frisar que ela foi reeditada pela MP no 2.200-1, de 27 de julho de 2001, a qual, por conseguinte, foi reeditada pela MP no 2.200-2, de 24 de agosto de 2001. Seu artigo $1^{\circ}$ regulamenta a finalidade da Infraestrutura de Chaves Públicas Brasileira, que é "garantir a autenticidade, a integridade e a validade jurídica de documentos em forma eletrônica, das aplicações de suporte e das aplicações habilitadas que utilizem certificados digitais, bem como a realização de transações eletrônicas seguras".

A MP no 2.200 instituiu a infraestrutura técnico-administrativa dos agentes que regularão e fornecerão os certificados digitais e, ainda, tratou dos efeitos jurídicos produzidos pela declaração volitiva assinada e certificada digitalmente, de acordo com a ICP-Brasil.

E vai mais além, pois trata, ainda, dos efeitos jurídicos originados de outros meios de comprovação de autoria, prevendo que uma autarquia federal se responsabilizará pela política legislativa de intervenção estatal, controlando e supervisionando as atividades dos prestadores de serviços de certificação digita ${ }^{25}$.

$\mathrm{O}$ assunto em questão exige a informação de que o Comitê Gestor é a autoridade encarregada de administrar a ICP-Brasil; é ele que promove o estabelecimento dos critérios e das normas para o credenciamento das entidades que compõem a rede de certificação digital e sua principal função é coordenar a implantação e o funcionamento da ICP-Brasil' ${ }^{26}$.

Vale aqui também destacar que o Instituto Nacional de Tecnologia da Informação (ITI) é uma autarquia federal vinculada à Casa Civil da Presidência da República e executa a função da Autoridade Certificadora Raiz (AC-Raiz); esta última compóe uma das partes fundamentais da ICP-Brasil. O ITI tem como

24 MENKE, F. op. cit., p.99.

25 Idem.

26 Ibidem., p. 100.

83 | ARGUMENTUM - Revista de Direito n. 11 - 2010 - UNIMAR 
função credenciar e fiscalizar as entidades integrantes da ICP-Brasil e, ainda, proporciona o funcionamento da AC-Raiz ${ }^{27}$.

De acordo com o artigo $5^{\circ}$ da MP no 2.200-2, a AC-Raiz tem a obrigação de emitir, expedir, distribuir, revogar e gerenciar os certificados das Autoridades Certificadoras de nível imediatamente subsequente ao seu, dentre outras funçōes, sendo vedado a ela emitir certificados para o usuário final, de acordo com o parágrafo único desse artigo. A AC-Raiz é a primeira autoridade da cadeia de certificação, sendo ela a executora das políticas de certificados e normas técnicas e operacionais aprovadas pelo Comitê Gestor da ICP-Brasil.

Por fim, é preciso entender que a chave privada diz respeito à informação que requer maior segurança e, para isso, é necessária a criação de um ambiente seguro tanto para o armazenamento de informaçōes quanto para o desempenho das operações realizadas pela AC-Raiz.

\section{Considerações finais}

A segurança na Internet, que há alguns anos tem sido motivo de discussões, sempre foi alvo de preocupação da maior parte dos indivíduos que dela se utilizam para a efetivação de contratos. Tal fato se deve à falta de ambientes seguros para a realização de tais acordos, considerando-se que a segurança é fator primordial na realização de qualquer contrato. Surge, assim, a necessidade da criação de instrumentos hábeis e capazes de proporcioná-la no meio virtual.

Diante desse fato, estudiosos da Informática e do Direito, visando garantir transparência, autenticidade, validade, confiabilidade e integridade aos documentos eletrônicos, desenvolveram novos mecanismos de segurança. Com isso, ressurgem antigos métodos de cifrar mensagens, de modo que somente o remetente e o destinatário poderão ter acesso ao conteúdo delas, codificando e, respectivamente, decodificando tais mensagens. À ciência de cifrar e decifrar mensagens é dado o nome de criptografia.

A partir do desenvolvimento da criptografia assimétrica foram criadas as assinaturas digitais, as quais possibilitam que a declaração de uma pessoa física ou jurídica, em meio virtual, seja identificada de forma segura. Cabe enfatizar que a principal incidência das assinaturas digitais ocorre justamente na celebração dos contratos eletrônicos.

Esse tipo de assinatura visa comprovar que a pessoa elaborou ou concorda com o documento eletrônico assinado e certificado digitalmente, além de propiciar a identificação do autor de determinado documento eletrônico, tal como a assinatura manuscrita, oferecendo, ainda, o nível desejado de segurança nos

27 MENKE, F. op. cit., p.101. 
contratos eletrônicos, pois informa com precisão quem é o autor de tal assinatura e indica que o documento não foi adulterado. Se o documento eletrônico for alterado, sua assinatura digital também o será e, detectada essa ocorrência, tornase inválida a assinatura.

Pela assinatura manuscrita em um documento, identificamos determinado indivíduo como se ela fosse a sua marca, enquanto que a assinatura digital liga um determinado sujeito a um documento eletrônico, garantindo sua autenticidade e integridade. A assinatura digital obrigatoriamente deve possuir uma variação, que inclui dados do documento na qual é inserida, enquanto a assinatura manuscrita, ao contrário, deve ser sempre igual, a fim de gerar a mesma presunção.

A assinatura digital é, notadamente, um dos requisitos mais desejados por ambas as partes envolvidas nos negócios on-line, empresários ou consumidores e, para que tal assinatura seja válida, é necessário que uma Autoridade Certificadora emita um certificado digital, comprovando a autenticidade do documento eletrônico assinado. Devido à necessidade de conhecimento do emissor de determinado documento eletrônico, foi criada a certificação digital e, com ela, as Autoridades Certificadoras.

Caberá à Autoridade Certificadora verificar se quem emitiu a chave pública é autorizado para tanto; ocorrida essa verificação, a Autoridade Certificadora emite um certificado digital, o qual garantirá sua validade jurídica. Essa certificação digital afiançará a veracidade da identidade do proprietário da chave.

O certificado digital contém informações essenciais, tais como: chave pública do autor do documento eletrônico, nome e endereço do e-mail do autor, data da validade da chave pública, nome da Autoridade Certificadora que emitiu o certificado digital, número de série do certificado digital e, por fim, assinatura da Autoridade Certificadora.

Com o crescimento do número de contratos celebrados em meio virtual, surge para o Direito a obrigação de buscar a proteção dos contratantes nas transações eletrônicas; a busca por ambientes seguros fez com que novas regras fossem criadas para atender às necessidades advindas deste crescimento.

O legislador brasileiro não ficou alheio a esse desenvolvimento e, assim, em junho de 2001, foi estabelecida a Infraestrutura de Chaves Públicas Brasileiras (ICP-Brasil), por intermédio da MP no 2.200-1, instituindo a Infraestrutura de Chaves Públicas do Poder Executivo Federal: a ICP-Gov. Com a criação da ICPBrasil deixou-se de atender com exclusividade à Administração Pública Federal, ampliando essa função para qualquer usuário que desejasse adquirir um certificado digital; sua última reedição foi em 24 de agosto de 2001, pela MP no 2.200-2.

Conforme seu artigo $1^{\circ}$, a finalidade da Infra-Estrutura de Chaves Públicas Brasileira é "garantir a autenticidade, a integridade e a validade jurídica de documentos em forma eletrônica, das aplicaçôes de suporte e das aplicaçôes 
habilitadas que utilizem certificados digitais, bem como a realização de transações eletrônicas seguras".

A MP no 2.200-1 instituiu a infraestrutura técnico-administrativa dos agentes que regularão e fornecerão os certificados digitais e, ainda, tratou dos efeitos jurídicos produzidos pela declaração volitiva assinada e certificada digitalmente de acordo com a ICP-Brasil. Essa medida confere validade jurídica à assinatura digital, atribuindo-lhe a mesma eficácia e validade jurídica de uma assinatura manual.

Segundo consta no artigo $5^{\circ}$ da MP no 2.200-2, a AC-Raiz, primeira autoridade da cadeia de certificação, tem, dentre outras funçôes, a obrigação de emitir, expedir, distribuir, revogar e gerenciar os certificados das Autoridades Certificadoras de nível imediatamente subsequente ao seu, sendo vedado a ela emitir certificados para o usuário final, de acordo com o parágrafo único deste artigo. A AC-Raiz é a executora das políticas de certificados e normas técnicas e operacionais aprovadas pelo Comitê Gestor da ICP-Brasil.

Desse modo, foi possível concluir que a assinatura digital, digitalmente certificada, diz respeito a um elemento primordial para tornar válido o contrato eletrônico. Quanto maior for o desenvolvimento tecnológico e a propagação do conhecimento entre os usuários da Internet para contratar, mais segurança será exigida dos métodos e dos equipamentos já existentes, tanto dos softwares quanto das assinaturas digitais, as quais proporcionam autenticidade e validade aos contratos eletrônicos.

\section{Referências}

ASSOCIAÇÃO BRASILEIRA DE NORMAS TÉCNICAS. NBR 10520: informação e documentação: citaçôes em documentos: apresentação. Rio de Janeiro, ago. 2002.

. NBR 14724: informação e documentação: trabalhos acadêmicos: apresentação. Rio de Janeiro, ago. 2002.

2002.

. NBR 6023: informação e documentação: Referências: elaboração. Rio de Janeiro, ago.

. NBR 6024: informação e documentação: numeração progressiva das seçôes de um documento escrito: apresentação. Rio de Janeiro, mai. 2003. 2003.

. NBR 6028: informação e documentação: Resumo: apresentação. Rio de Janeiro, nov.

. NBR 6029: informação e documentação: livros e folhetos: apresentação. Rio de Janeiro, set. 2002.

BEHRENS, F. Assinatura eletrônica \& negócios jurídicos. Curitiba: Juruá, 2007.

BOIAGO JÚNIOR, J. W. Contratação eletrônica: aspectos jurídicos. Curitiba: Juruá, 2005. 
BRASIL, A. B. Assinatura digital. Jus Navigandi, ano 4, n. 40. Teresina, mar. 2000. Disponível em: <http://jus2.uol.com.br/doutrina/texto.asp?id=1782>. Acesso em: 13 set. 2007.

CASTRO, A. A. O documento eletrônico e a assinatura digital. Disponível em: <http://jus2.uol. com.br/doutrina/texto.asp?id=2632\&p=2>. Acesso em: 13 set. 2007 .

CORRÊA, G. T. Aspectos jurídicos da internet. São Paulo: Saraiva, 2000.

GANDINI, J. A. D.; SALOMÃO, D. P. S.; JACOB, C. A segurança dos documentos digitais. Disponível em: <http://jus2.uol.com.br>. Acesso em: 19 ago. 2005.

KUBIÇA, S. Documentos com segurança na internet. Disponível em: <http://www.pr.gov. br/batebyte/edicoes/2001/bb107/documentos.htm>. Acesso em: 15 out. 2007.

MARQUES, A. T. G. L. A prova documental na internet. Curitiba: Juruá, 2007.

MÉNDEZ, M V. Las Pruebas en el Comercio Electrónico. Revista de Derecho Informático. Disponível em: <http://www.alfa-redi.org>. Acesso em: 26 set. 2007.

MENKE, F. Assinatura eletrônica: aspectos jurídicos no direito brasileiro. São Paulo: Revista dos Tribunais, 2005.

SOUZA, V. R. P. Consumidor virtual de bens e o seu direito de arrependimento. 2005. Monografia de Mérito (Graduação em Direito). Faculdade de Direito de Presidente Prudente, Faculdades Integradas "Antônio Eufrásio de Toledo" de Presidente Prudente, 2005.

; CATANA, L. L. T. O. Consumidor na Era Virtual. In: I ENCONTRO DE INICIAÇÃO CIENTÍFICA DA TOLEDO, 1., 2005, Presidente Prudente, SP. Anais. Presidente Prudente: Studio Águia Pro-áudio, 2005. 1 CD-ROM.

; CATANA, L. L. T. O. Consumidor Virtual. Toledo News. Presidente Prudente, 1 fev. 2005. Folha Opinião, p. 7.

; CATANA, L. L. T. O. Consumidor: direitos e obrigações. In: CATANA, L. L. T. O. Direito de arrependimento e a possibilidade de sua aplicação no comércio Eletrônico. Academia Brasileira de Direito. São Paulo, 2 jun. 2006. Disponível em: <http://www.abdir.com.br/artigos/ ver.asp?art_id=224\&orderby=data_Down\&page $=1 \&$ SearchFor $=$ prioli\&Search Where $=$ autor $>$. Acesso em: 26 jul. 2007.

SOUZA, V. R. P.; CATANA, L. L. T. O. Direitos Reais no Consumo Virtual. In: II ENCONTRO DE INICIAÇÃO CIENTÍFICA DA TOLEDO, 2., 2006, Presidente Prudente, SP. Anais. Presidente Prudente: Studio Águia Pró-audio, 2006. 1 CD-ROM.

; CATANA, L. L. T. O. Internet: realidade inegável. Jornal Oeste Notícias. Presidente Prudente, 19 mar. 2005. Folha Opinião, p. 1.2.

; CATANA, L. L. T. O. Mundo Virtual. Folha Regional. Palmital, 24 mar. 2005. Folha Colunista, p. 4.

; CATANA, L. L. T. O. O Desenvolvimento Inegável do Comércio Eletrônico. Revista Jurídica UNIGRAN. Dourados, v. 8, n. 15, p. 245-273, jan.-jun. 2006.

; GITAHY, R. R. C. Consumidor Virtual e o Direito de Arrependimento. In: XIV ENCONTRO PREPARATÓRIO PARA O CONGRESSO NACIONAL DO CONPEDI 2005, 14, 2005, Marília, SP. Anais. Florianópolis: Fundação Boiteux, 2005, p. 155-161. 
ZOCCOLI, D. Autenticidade e integridade dos documentos eletrônicos: a firma eletrônica. In: ROVER, A. J. (Org.). Direito, sociedade e informática. Florianópolis: Fundação Boiteux, 2000.

Recebido em 15/07/2009

Aceito para publicação em 08/02/2010 